\title{
Ocorrência e fatores de risco associados às infecções por Toxoplasma gondii e Neospora caninum em cães no município de Natal, Estado do Rio Grande do Norte, Nordeste do Brasil
}

\author{
Occurrence and risk factors associated with Toxoplasma gondii and Neospora caninum infections in \\ dogs in the county of Natal, Rio Grande do Norte state, Northeastern Brazil
}

\author{
Sabrina Barros Araujo Dantas ${ }^{\mathrm{I}}$ Annielle Regina da Fonseca Fernandes ${ }^{\mathrm{I}}$ \\ Orestes Luiz de Souza Neto II Rinaldo Aparecido Mota ${ }^{\text {II }}$ Clebert José Alves ${ }^{\text {I }}$ \\ Sérgio Santos de Azevedo ${ }^{\mathrm{I}^{*}}$
}

\section{RESUMO}

O objetivo do presente trabalho foi determinar a frequência de anticorpos anti-Toxoplasma gondii e anti-Neospora caninum, bem como identificar fatores de risco em cães do município de Natal, Estado do Rio Grande do Norte, Nordeste do Brasil. Para tanto, foram colhidas amostras de sangue de 476 cães atendidos em clínicas veterinárias no período de março de 2011 e maio de 2012. Para o diagnóstico sorológico das infecções, foi utilizada a reação de imunofluorescência indireta (RIFI), adotandose como pontos de corte as diluições 1:64 (T. gondii) e 1:50 (N. caninum). Das 476 amostras, 55 (11,5\%; IC 95\%=8,8\%-14,8\%) foram soropositivas para T. gondii, e 31 (6,5\%; IC 95\%=4,5\%$9,1 \%)$ para $N$. caninum. As variáveis idade $>48$ meses $(O R=4,68)$ e acesso à rua $(O R=4,91)$ foram identificadas como fatores de risco para T. gondii, enquanto que para $N$. caninum, os fatores de risco foram limpeza semanal/quinzenal/mensal do ambiente onde $o$ animal vive $(O R=2,77)$ e presença de ratos $(O R=2,34)$. Concluise que as infecções por T. gondii e N. caninum, detectadas por sorologia, estão presentes em cães atendidos em clínicas veterinárias do município de Natal, bem como se recomenda a correção dos fatores de risco identificados.

Palavras-chave: toxoplasmose, neosporose, sorologia, epidemiologia, cães.

\section{ABSTRACT}

The aim of this survey was to determine the frequency of anti-Toxoplasma gondii and anti-Neosporacaninum antibodies, as well as to identify risk factors in dogs from the county of Natal, Rio Grande do Norte state, Northeastern Brazil. Blood samples were collected from 476 dogs attended at veterinary clinics from March 2011 to May 2012. For the serological diagnosis of the infections the indirect fluorescent antibody test (IFAT) adopting the dilutions 1:64 (T. gondii) and 1:50 (N. caninum) as cut-off points, was used. Of the 476 samples 55 (11.5\%, 95\% CI=8.8\%-14.8\%) were seropositive to T. gondii, and 31 (6.5\%, $95 \% \mathrm{CI}=4.5 \%-9.1 \%)$ to
$N$. caninum. The variables age $>48$ months $(O R=4.68)$ and access to street $(O R=4.91)$ were identified as risk factors for $\mathbf{T}$. gondii, while for $N$. caninum, risk factors were weekly/fortnightly/monthly cleaning of the environment where the animal stay $(O R=2.77)$ and presence of rodents $(O R=2.34)$. It is concluded that infectionsdue to $\mathbf{T}$. gondii and $\mathbf{N}$. caninum detected by serology are present in dogs attended at veterinary clinics in the county of Natal, as well as it is recommended the correction of the risk factors identified.

Key words: toxoplasmosis, neosporosis, serology, epidemiology, dogs.

\section{INTRODUÇÃO}

Toxoplasma gondii e Neospora caninum são dois protozoários relacionados que apresentam ampla distribuição geográfica e causam doença neurológica em cães. Ambos os agentes podem infectar várias espécies de animais e possuem ciclo biológico no qual carnívoros são hospedeiros definitivos. $\mathrm{Na}$ infecção por T. gondii, os felídeos atuam como hospedeiros definitivos, enquanto que, na infecção por $N$. caninum, os canídeos domésticos e algumas espécies de canídeos silvestres são hospedeiros definitivos (GONDIM et al., 2004; DUBEY, 2010; GUIMARÃES, 2011).

O ciclo biológico desses coccídeos é heteroxênico, alternando-se em duas fases distintas: uma sexuada que só ocorre no hospedeiro definitivo e outra assexuada que ocorre tanto nos hospedeiros definitivos quanto nos hospedeiros intermediários. Morfologicamente, são observados três estágios

'Unidade Acadêmica de Medicina Veterinária (UAMV), Centro de Saúde e Tecnologia Rural (CSTR), Universidade Federal de Campina Grande (UFCG), Patos, PB, Brasil. E-mail: ssazevedo@cstr.ufcg.edu.br.*Autor para correspondência.

"Universidade Federal Rural de Pernambuco (UFRPE), Recife, PE, Brasil. 
infecciosos: os taquizoítos, os bradizoítos e os esporozoítos, que diferem entre si quanto a características específicas (SPEER et al., 1999; DUBEY, 2010).

A infecção por esses protozoários pode cursar de forma assintomática ou desencadear sintomatologia difusa, que pode ser facilmente confundida com várias outras doenças, resultando em quadros com sinais clínicos e sintomas genéricos, dificultando o diagnóstico clínico e a adoção de medidas para o tratamento e controle, sendo o diagnóstico laboratorial uma ferramenta indispensável. Dentre as técnicas de diagnóstico existentes, a reação de imunofluorescência indireta (RIFI) é preconizada como padrão ouro, podendo ser usada tanto na fase aguda (pesquisa de $\operatorname{IgM}$ ) quanto na fase crônica (pesquisa de IgG) (CAMARGO, 1974; DUBEY et al., 1988; DUBEY, 2010).

Em seres humanos, na maioria das vezes, a toxoplasmose é assintomática, porém, a infecção durante a gestação pode causar abortamento, retardo motor e mental ou perda da visão. O grau de infecção transplacentária e os efeitos danosos da multiplicação do T. gondii no feto dependem da época gestacional em que a infecção ocorreu (DIAS \& FREIRE, 2005). LUFT \& REMINGTON (1992) estimaram que, em pacientes com síndrome da imunodeficiência adquirida (SIDA), a taxa de mortalidade para toxoplasmose variade $3 \%$ a $20 \%$. Para $N$. caninum, existem evidências sorológicas em seres humanos, no entanto, não foram descritos relatos comprovados da doença. Por outro lado, tal possibilidade não pode ser descartada (TRANAS et al., 1999; LOBATO et al., 2006).

A condução de estudos epidemiológicos para toxoplasmose e neosporose em cães assume importância, tendo em vista o seu convívio mais estreito e prolongado com seres humanos. Esses animais podem atuar como sentinelas sorológicas para T. gondii e são hospedeiros definitivos na infecção por $N$. caninum, de maneira que a obtenção de informações epidemiológicas pode auxiliar os serviços de vigilância na adoção de ações para a prevenção e o controle dessas doenças (ULLMANN et al., 2008; COIRO et al., 2011).

Apesar de vários estudos apontarem a ocorrência de anticorpos anti-T. gondii e anti- $\boldsymbol{N}$. caninum em cães no Brasil, são escassas as pesquisas conduzidas em cães na região Nordeste, especialmente no município de Natal, capital do Estado do Rio Grande do Norte. Dessa maneira, o objetivo do presente trabalho foi determinar a frequência de anticorpos anti-T. gondiie anti- $N$. caninum, bem como identificar fatores de risco em cães do município de Natal, Estado do Rio Grande do Norte, Nordeste do Brasil.

\section{MATERIAL E MÉTODOS}

A pesquisa foi realizada no município de Natal, capital do Estado do Rio Grande do Norte. Foram colhidas 476 (mediana $=41 ;$ mínimo $=12$; máximo $=129$ ) amostras de soro de cães domiciliados de ambos os sexos, de raças variadas e com idade acima de três meses, que foram atendidos em dez clínicas veterinárias localizadas em diversos pontos da cidade (Figura 1), no período de março de 2011 e maio de 2012. A seleção dos cães foi realizada de acordo com a autorização do proprietário, além da condição corporal na qual os animais se encontravam no momento da consulta. Foram selecionados cães com escore de condição corporal de no mínimo 4, conforme sistema de interpretação descrito por LAFLAMME (1997).

As colheitas de sangue foram efetuadas por venopunção cefálica ou jugular externa, utilizando-se seringas descartáveis de $5 \mathrm{~mL}$, com posterior obtenção do soro e estocagem a $-20^{\circ} \mathrm{C}$ até a realização da sorologia. O proprietário que autorizou a participação do seu cão na pesquisa respondeu a um questionário epidemiológico que continha informações sobre possíveis fatores de risco associados à exposição aos agentes. O questionário foi elaborado de modo a propiciar o fácil entendimento das questões por parte do proprietário, contendo perguntas objetivas e de múltipla escolha, com exceção da idade dos animais. Em cada clínica, foi viabilizado um entrevistador previamente treinado, com o objetivo de evitar ou pelo menos minimizar a ocorrência de vieses durante a aplicação do questionário. As informações obtidas com os questionários foraminseridas em banco de dados elaborado com o programa Microsoft Access ${ }^{\circledR}$.

A detecção de anticorpos anti-T. gondii foi realizada com a RIFI, segundo metodologia descrita por CAMARGO (1974). Foram utilizadas lâminas sensibilizadas com taquizoítas da cepa RH, mantida em camundongos. Para a detecção de anticorpos anti- $\boldsymbol{N}$. caninum, também foi utilizada a RIFI, segundo DUBEY et al. (1988), empregandose lâminas sensibilizadas com a cepa $\mathrm{NC}-1$, obtida a partir de cultivo de células vero. Os pontos de corte adotados foram título $\geq 16$ para $\boldsymbol{T}$. gondii e $\geq 50$ para $N$. caninum. Para a visualização da reação, foi utilizado conjugado comercial anti-IgGcanino (Sigma, USA), marcado com isotiocianato de fluoresceína. 


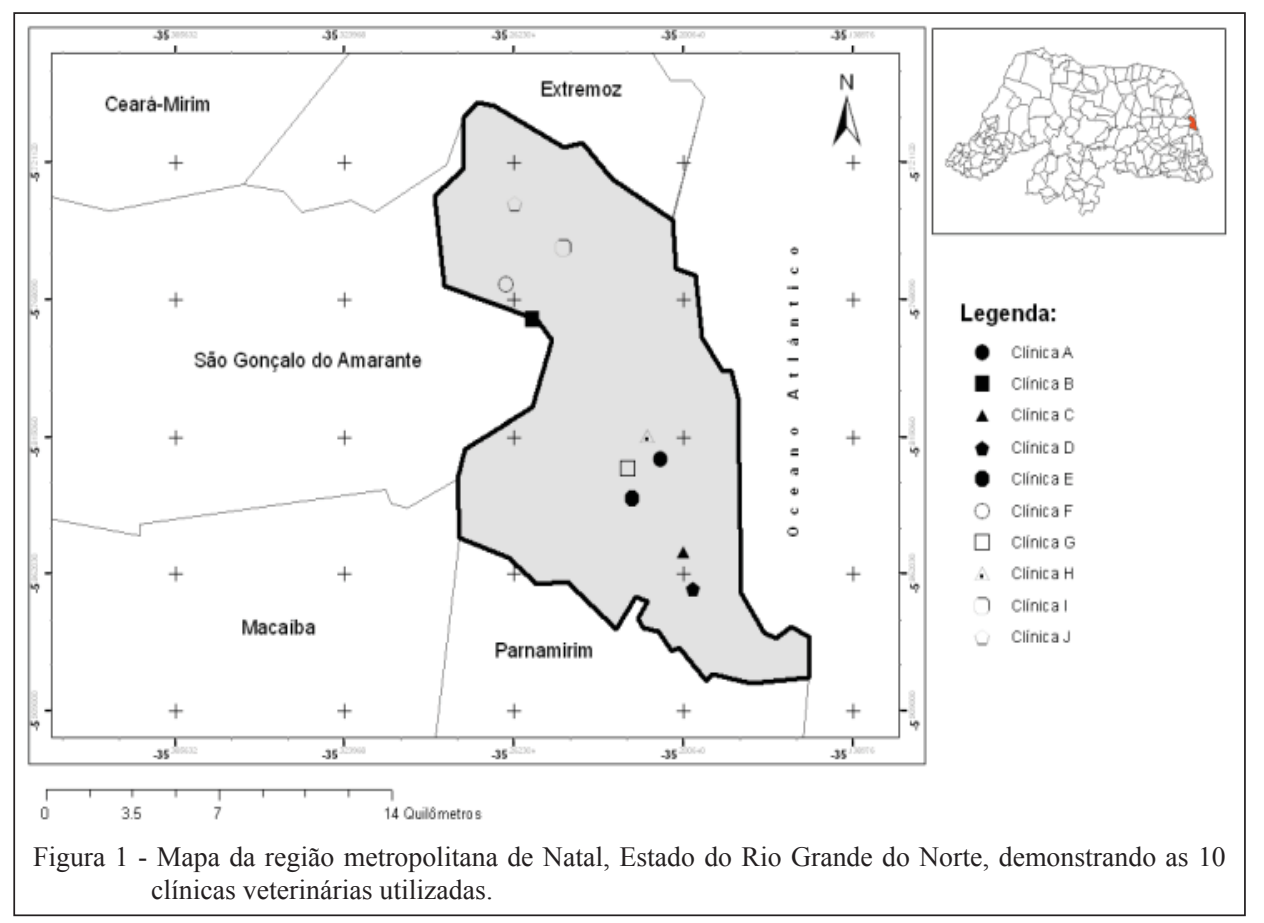

As amostras que apresentaram taquizoítos com fluorescência periférica total foram consideradas positivas e submetidas a diluições sucessivas, adotando-se como título final o correspondente àúltima diluição com reação positiva.

Foi calculado o intervalo de confiança de 95\% (IC 95\%) binomial exato para as frequências de soropositividade para T. gondii e $N$. caninum.Os dados obtidos com os questionários epidemiológicos foram analisados estatisticamente em duas etapas (análise univariável e análise multivariável) para a determinação dos possíveis fatores de risco, associados à soropositividade para T. gondii e $N$. caninum. Na análise univariável, foram formados dois grupos de animais, soropositivos e soronegativos, de acordo com o resultado da sorologia (variável dependente), que foram comparados frente às variáveis analisadas (variáveis independentes). Aquelas variáveis independentes que apresentaram valor de $P \leq 0,2$ pelo teste de qui-quadrado ou teste exato de Fisher foram selecionadas para a análise multivariável, utilizando-se regressão logística múltipla(HOSMER \& LEMESHOW, 2000). O ajuste do modelo final foi verificado com o teste de Hosmer e Lemeshow, pelo qual um valor de $P \geq 0,5$ indicou ajuste satisfatório. A colinearidade entre as variáveis independentes foi verificada utilizando-se análise de correlação e, quando duas variáveis apresentaram correlação forte (coeficiente de correlação $>0,90$ ), apenas uma foi selecionada para a análise multivariável, de acordo com a plausibilidade biológica (DOHOO et al., 1996). Adicionalmente, a variável idade foi inserida nos modelos como possível variável de confusão para verificação de mudanças substanciais $(>10 \%)$ nos estimadores. O nível de significância adotado foi de $5 \%$, e as análises foram realizadas com o programa SPSS 20.0 for Windows.

\section{RESULTADOS E DISCUSSÃO}

O uso de amostragem por conveniência em estudos soroepidemiológicos é muito comum e permite o levantamento de informações importantes. No entanto, inferência epidemiológica não deve ser feita a partir dessa metodologia em decorrência da possibilidade de vieses, principalmente no tocante à ocorrência de viés de seleção. Em estudos que envolvem a seleção de cães a partir de clínicas veterinárias, é muito difícil evitar a ocorrência de tais vises, no entanto, com a metodologia empregada no presente trabalho procurou-se minimizá-los ao máximo.

Dos 476 cães utilizados, 55 (11,5\%; IC $95 \%=8,8 \%-14,8 \%$ ) foram soropositivos para a pesquisa de anticorpos anti-T. gondii, sendo $26(47,2 \%), 12$ (22\%), dez (18\%), seis (11\%) e um $(1,8 \%)$ animais soropositivos com títulos 64, 128, 256, 512 e 1024, respectivamente. A soropositividade por clínica 
variou de $0 \%$ a $22,5 \%$. A frequência observada neste estudo é baixa quando comparada às obtidas em outros estados brasileiros, como Rondônia, 76,4\% (CAÑON-FRANCO et al., 2004) e Paraíba, 45,1\% (AZEVEDO et al., 2005).

Para $N$. caninum, $31(6,5 \%$; IC $95 \%=4,5 \%$ $9,1 \%$ ) animais foram soropositivos, sendo oito $(25,8 \%)$, sete $(22,6 \%)$, quatro $(12,9 \%)$, cinco $(16,1 \%)$ e sete $(22,6 \%)$ com títulos 50, 100, 200, 400 e 800 , respectivamente. A soropositividade por clínica variou de $0 \%$ a $20 \%$.Estudos sorológicos conduzidos no Brasil em populações caninas com características similares a do presente trabalho revelaram ampla variação de soropositividade para esse agente, desde $1,98 \%$ em São Paulo (COIRO et al., 2011) até 45\% no Maranhão (TEIXEIRA et al., 2006).

As diferenças nas frequências de soropositividade encontradas no presente trabalho com as observadas em outros estudos podem ser decorrentes de vários fatores, como tamanho amostral, teste diagnóstico utilizado, período de realização do estudo e características individuais da população canina estudada (CAÑÓN-FRANCO et al., 2003; AZEVEDO et al., 2005). Aliado a isso, todos os animais amostrados foram incluídos no estudo durante atendimento ambulatorial, característica que reflete maior cuidado dos proprietários com os animais, o que poderia justificar a baixa frequência de soropositividade, tanto para T. gondii quanto para N. caninum.

Nas análises de fatores de risco para $\boldsymbol{T}$. gondii e $N$. caninum, não foi observada colinearidade entre as variáveis independentes, bem como não foi verificado efeito confundidor da variável idade. $\mathrm{Na}$ análise univariável dos fatores de risco para $\mathrm{T}$. gondii, as variáveis idade, acesso à rua, contato com bovinos, contato com gatos, passear com o cão, viajar com o cão, presença de ratos e acesso a açudes foram selecionadas $(\mathrm{P} \leq 0,2)$ para a análise multivariável (Tabela 1). Contudo, ao submetê-las à análise de regressão logística, as variáveis acesso à rua e idade superior a 48 meses foram identificadas como fatores de risco (Tabela 2). O modelo final apresentou ajuste satisfatório (teste de Hosmer e Lemeshow: $\chi^{2}=0,410$; $\mathrm{P}=0,815)$.

Considerando a idade dos animais como fator de risco para a infecção por T. gondii, notase que animais com idade superior a 48 meses apresentaram 4,68 vezes mais chance de serem soropositivos, em comparação com animais com idade de três a 12 meses, resultado que corrobora os descritos por CAÑÓN-FRANCO et al. (2004) e AZEVEDO et al. (2005), que referiram maior ocorrência de soropositivos entre animais com idade avançada, ressaltando a importância da infecção pósnatal e a maior possibilidade de acesso às fontes de infecção e vias de transmissão em função da idade.

Animais com acesso à rua tiveram 4,91 vezes mais chance de serem soropositivos para T. gondii, resultado que concorda com os obtidos por CAÑÓN-FRANCO et al. (2004) e MOURA et al. (2009), que também descreveram essa variável como fator de risco para a infecção, o que pode ser justificado pela maior chance de esses animais entrarem em contato com fontes de infecção e vias de transmissão do agente.

Para $N$. caninum, as variáveis selecionadas na análise univariável foram $(\mathrm{P} \leq 0,2)$ : contato com animais silvestres, limpeza (com desinfetante) do ambiente onde o cão vive, presença de ratos e acesso à açudes (Tabela 1). Na regressão logística, presença de ratos e limpeza semanal/quinzenal/mensal do ambiente onde o animal vive foram identificados como fatores de risco (Tabela 2). O modelo final também apresentou ajuste satisfatório (teste de Hosmer e Lemeshow: $\left.\chi^{2}=0,580 ; \mathrm{P}=0,748\right)$.

No presente trabalho, cães cujos proprietários relataram a presença de ratos no domicílio apresentaram 2,34 vezes mais chances de serem soropositivos para $N$. caninum. FERROGLIO et al. (2007) e MEERBURG et al. (2012) afirmaram que, no ciclo silvestre, os roedores naturalmente infectados funcionam como reservatórios, desempenhando papel importante na manutenção e disseminação do agente, havendo a possibilidade de os cães contraírem a infecção ao ingeri-los. Some-se a isso o fato de que, em várias ocasiões, $N$. caninum foi identificado em ratos e camundongos de vida livre naturalmente infectados (HUANG et al., 2004; FERROGLIO et al., 2007; JENKINS et al., 2007).

ALVES NETO (2009) determinou que oocistos de $N$. caninum são inviabilizados após tratamento com hipoclorito de sódio a $10 \%$ durante uma hora em temperatura ambiente, recomendando o uso desse desinfetante na descontaminação de ambientes contra oocistos. No presente trabalho, animais que vivem em ambientes onde a limpeza com desinfetante é realizada semanal, quinzenal ou mensalmente possuem 2,77 vezes mais chances de serem soropositivos para $N$. caninum, em comparação com a limpeza diária. Essa informação reforça a necessidade de limpeza periódica do ambiente onde os animais permanecem, uma vez que o grau de contaminação poderá favorecer a permanência e viabilidade de oocistos, contribuindo para a transmissão horizontal do agente. 
Tabela 1 -Análise univariável para os fatores de risco associados com a soropositividade para $\mathbf{T}$. gondiie $\boldsymbol{N}$. caninum em 476 cães do município de Natal, Rio Grande do Norte, no período de março de 2011 a maio de 2012.

\begin{tabular}{|c|c|c|c|c|c|}
\hline \multirow{2}{*}{ Variável/categoria } & \multirow{2}{*}{ № total de animais } & \multicolumn{2}{|c|}{-----Soropositividade para $\boldsymbol{T}$. gondii----- } & \multicolumn{2}{|c|}{----Soropositividade para N. Caninum---- } \\
\hline & & № de soropositivos $(\%)$ & $\mathrm{P}$ & $\mathrm{N}^{\mathrm{o}}$ de soropositivos $(\%)$ & $\mathrm{P}$ \\
\hline \multicolumn{6}{|l|}{ Sexo } \\
\hline Macho & 218 & $28(12,8)$ & & $12(5,5)$ & \\
\hline Fêmea & 258 & $27(10,5)$ & 0,506 & $19(7,4)$ & 0,527 \\
\hline \multicolumn{6}{|l|}{ Idade } \\
\hline $3-12$ meses & 55 & $2(3,6)$ & & $5(9,1)$ & \\
\hline 13 - 48 meses & 172 & $17(9,9)$ & & $13(7,6)$ & \\
\hline$>48$ meses & 249 & $36(14,5)$ & $0,052 *$ & $13(5,2)$ & 0,451 \\
\hline \multicolumn{6}{|l|}{ Raça } \\
\hline Sem raça definida & 129 & $18(14)$ & & $9(7,0)$ & \\
\hline Com raça definida & 347 & $37(10,7)$ & 0,403 & $22(6,3)$ & 0,967 \\
\hline \multicolumn{6}{|l|}{ Acesso à rua } \\
\hline Não & 426 & $39(9,2)$ & & $28(6,6)$ & \\
\hline Sim & 50 & $16(32)$ & $<0,001^{*}$ & $3(6,0)$ & 1,000 \\
\hline \multicolumn{6}{|l|}{ Alimentação } \\
\hline Ração comercial & 283 & $33(11,7)$ & & $19(6,7)$ & \\
\hline Alimento caseiro & 26 & $3(11,5)$ & & $0(0,0)$ & \\
\hline Ambos & 167 & $19(11,4)$ & 0,996 & $12(7,2)$ & 0,376 \\
\hline \multicolumn{6}{|l|}{ Contato com cães } \\
\hline Não & 236 & $23(9,7)$ & & $17(7,2)$ & \\
\hline Sim & 240 & $32(13,3)$ & 0,280 & $14(5,8)$ & 0,675 \\
\hline \multicolumn{6}{|l|}{ Contato com bovinos } \\
\hline Não & 472 & $53(11,2)$ & & $31(6,6)$ & \\
\hline Sim & 4 & $2(50,0)$ & $0,068 *$ & $0(0,0)$ & 1,000 \\
\hline \multicolumn{6}{|l|}{ Contato com gatos } \\
\hline Não & 410 & $43(10,5)$ & & $27(6,6)$ & \\
\hline Sim & 66 & $12(18,2)$ & $0,108 *$ & $4(6,1)$ & 1,000 \\
\hline \multicolumn{6}{|l|}{$\begin{array}{l}\text { Contato com animais } \\
\text { silvestres }\end{array}$} \\
\hline Não & 432 & $49(11,3)$ & & $31(7,2)$ & \\
\hline Sim & 44 & $6(13,6)$ & 0,837 & $0(0,0)$ & $0,100 *$ \\
\hline \multicolumn{6}{|l|}{ Ambiente onde o cão vive } \\
\hline Terra & 18 & $3(16,7)$ & & $2(11,1)$ & \\
\hline Cimento & 246 & $23(9,3)$ & & $14(5,7)$ & \\
\hline Ambos & 212 & $29(13,7)$ & 0,277 & $15(7,1)$ & 0,604 \\
\hline \multicolumn{6}{|l|}{$\begin{array}{l}\text { Frequência de limpeza } \\
\text { (com desinfetante) do } \\
\text { ambiente onde o cão vive }\end{array}$} \\
\hline Diária & 400 & $44(11)$ & & $21(5,2)$ & \\
\hline Semanal/quinzenal/mensal & 76 & $11(14,5)$ & 0,501 & $10(13,2)$ & $0,019^{*}$ \\
\hline \multicolumn{6}{|l|}{ Passeia com o cão } \\
\hline Não & 210 & $30(14,3)$ & & $16(7,6)$ & \\
\hline Sim & 266 & $25(9,4)$ & $0,131 *$ & $15(5,6)$ & 0,495 \\
\hline \multicolumn{6}{|l|}{ Viaja com o cão } \\
\hline Não & 401 & $52(13,0)$ & & $27(6,7)$ & \\
\hline Sim & 75 & $3(4,0)$ & $0,042 *$ & $4(5,3)$ & 0,802 \\
\hline \multicolumn{6}{|l|}{ Presença de ratos } \\
\hline Não & 250 & $23(9,2)$ & & $10(4,0)$ & \\
\hline Sim & 226 & $32(14,2)$ & $0,122 *$ & $21(9,3)$ & $0,032 *$ \\
\hline \multicolumn{6}{|l|}{ Acesso do cão a açudes } \\
\hline Não & 421 & $44(10,5)$ & & $24(5,7)$ & \\
\hline Sim & 55 & $11(20,0)$ & $0,063 *$ & $7(12,7)$ & $0,073 *$ \\
\hline
\end{tabular}

* Variáveis selecionadas para a regressão logística múltipla $(\mathrm{P} \leq 0,2)$. 
Tabela 2 - Fatores de risco associados com a soropositividade para T. gondiie $\boldsymbol{N}$. caninum em 476 cães do município de Natal, Rio Grande do Norte, no período de março de 2011 a maio de 2012.

\begin{tabular}{|c|c|c|c|}
\hline Fator de risco & Oddsratio (OR) & IC $95 \%$ & $\mathrm{P}$ \\
\hline \multicolumn{4}{|l|}{ Infecção por T.gondii* } \\
\hline Idade $>48$ meses & 4,68 & $1,07-20,44$ & 0,040 \\
\hline Acesso à rua & 4,91 & $2,45-9,81$ & 0,001 \\
\hline \multicolumn{4}{|c|}{ 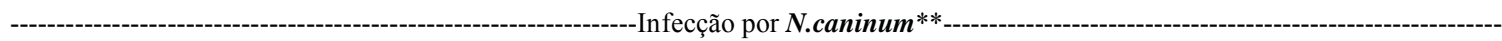 } \\
\hline Presença de ratos & 2,34 & $1,06-5,12$ & 0,034 \\
\hline
\end{tabular}

* Teste de Hosmer e Lemeshow: $\chi^{2}=0,410 ; \mathrm{P}=0,815$.

** Teste de Hosmer e Lemeshow: $\chi^{2}=0,580 ; \mathrm{P}=0,748$.

\section{CONCLUSÃO}

Os resultados apresentados indicam que as infecções por T. gondii e $\boldsymbol{N}$. caninum, detectadas por sorologia, estão presentes em cães atendidos em clínicas veterinárias do município de Natal. Com base na análise de fatores de risco, recomenda-se evitar o acesso irrestrito dos cães à rua, a realização frequente de limpeza do ambiente onde eles vivem e a adoção de medidas para o controle de roedores.

\section{AGRADECIMENTOS}

Ao Prof. Dr. Luis Fernando Pita Gondim, da Universidade Federal da Bahia (UFBA), pelo fornecimento da cepa de $N$. caninum, utilizada na sorologia. À Coordenação de Aperfeiçoamento de Pessoal de Nível Superior (CAPES), pela concessão de bolsa de Mestrado ao primeiro autor.

\section{COMITÊ DE ÉTICA E BIOSSEGURANÇA}

O referido trabalho foi aprovado pelo Comitê de Ética em Pesquisa do Centro de Saúde e Tecnologia Rural da Universidade Federal de Campina Grande (CEP/CSTR/UFCG), sob o número de protocolo 22/20012.

\section{REFERÊNCIAS}

ALVES NETO, A.F. Avaliação da viabilidade de oocistos esporulados de Neosporacaninum a diferentes condições de temperatura e ação de desinfetantes. 2009. 68f. Dissertação (Mestrado em Epidemiologia Experimental Aplicada às Zoonoses) - Programa de Pós-graduação em Epidemiologia Experimental Aplicada às Zoonoses, Faculdade de Medicina Veterinária e Zootecnia, Universidade de São Paulo, SP.

AZEVEDO, S.S. et al.Seroepidemiology of Toxoplasma gondii and Neosporacaninumin dogs from the state of Paraiba, Northeast region of Brazil. Research in Veterinary Science, v.79, n.1, p.51-56, 2005. Disponívelem: <http://www.sciencedirect.com/science/article/pii/ S0034528804001936>. Acesso em: 02 out. 2012.doi:10.1016/j. rvsc. 2004.10.001.

CAÑÓN-FRANCO, W.A. et al. Prevalence of antibodies to Neosporacaninumin dogs from Amazon, Brazil.
VeterinaryParasitology, v.115,p.71-74,2003.Disponível em: $<$ http:// www.sciencedirect.com/science/article/pii/S0304401703001316>. Acessoem: 10 nov. 2012.doi:10.1016/S0304-4017(03)00131-6.

CAÑÓN-FRANCO, W.A. et al. Occurrence of anti-Toxoplasma gondiiantibodies in dogs in the urban area of Monte Negro, Rondônia, Brazil.Veterinary Research Communications, v.28, p.113-118, 2004. Disponível em: <http://link.springer.com/article /10.1023\%2FB\%3AERC.0000012114.71235.73>. Acesso em: 10 nov. 2012.doi:10.1023/B:VERC.0000012114.71235.73.

CAMARGO, M.E. Introdução às técnicas de imunofluorescência. Revista Brasileira de Patologia Clínica, v.10, p.143-171, 1974.

COIRO, C.J. et al. Fatores de risco para leptospirose, leishmaniose, neosporose e toxoplasmose em cães domiciliados e peridomiciliados em Botucatu-SP. Veterinária e Zootecnia, v.18, n.3, p.393-407, 2011. Disponível em:<http://www.fmvz.unesp.br/ rvz/index.php/rvz/article/view/111/133>. Acesso em: 20 dez.2012.

DIAS, R.A.F.; FREIRE, R.L. Surtos de toxoplasmose em seres humanos e animais. Semina: Ciências Agrárias, v.26, n.2, p.239248, 2005.

DOHOO, I.R. et al. An overview of techniques for dealing with large numbers of independent variables in epidemiologic studies. Preventive Veterinary Medicine, v.29, n.3, p.221-239, 1996. Disponível em: <http://www.sciencedirect.com/science/article/ pii/S0167587796010744>. Acesso em: 19 dez. 2012.doi:0.1016/ S0167-5877(96)01074-4.

DUBEY, J.P. et al. Neonatal Neosporacaninum infection in dogs: isolation of the causative agent and experimental transmission. Jounal of American Veterinary Association, v.192, p.12691285, 1988. Disponível em: <http://www.ncbi.nlm.nih.gov/ pubmed/3144521>. Acesso em: 01 nov. 2012.

DUBEY, J.P. Toxoplasmosis of animals and humans. Boca Raton: CRC, Taylor \& Francis Group, 2010. 2v.

FERROGLIO, E. et al. Evidence of Neosporacaninum DNA in wild rodents.Veterinary Parasitology, v.148, n.3-4, p.346-349, 2007. Disponível em: <http://www.sciencedirect.com/science/ article/pii/S0304401707003275>. Acesso em: 02 jan. 2013.doi: 10.1016/j.vetpar.2007.06.031

GONDIM, L.F.P. et al. Coyotes (Canislatrans) are definitive hosts of Neosporacaninum. International Journal for Parasitology, v.34, n.2, p.159-161, 2004. Disponível em: <http://www. 
sciencedirect.com/science/article/pii/S0020751904000025>. Acesso em: 11 mar. 2012. doi: 10.1016/j.ijpara.2004.01.001.

GUIMARÃES, M.S. Ciclo silvestre de Neosporacaninum e sua importância na epidemiologia para os animais domésticos. 2011. 26f. Tese (Doutorado em Ciência Animal) - Programa de Pós-graduação em Ciência Animal, Universidade Federal de Goiás, GO

HOSMER, D.W.; LEMESHOW, S. Applied logistic regression. New York: John Wiley \& Sons, 2000. 375p.

HUANG, C.C. et al.Finding of Neosporacaninumin the wild brown rat (Rattusnorvegicus).Veterinary Research, v.35, n.3, p.283-290, 2004.Disponível em:<http://www.vetres-archive.org// file/Vet.Res._09284249_2004_35_3/ART0003.pdf>. Acesso em: 02 jan. 2013. doi:10.1051/vetres:2004010.

JENKINS, M.C. et al. Neospora caninum detected in feral rodents. Veterinary Parasitology, v.143, n.2, p.161-165, 2007. Disponível em: <http://www.sciencedirect.com/science/article/ pii/S0304401706004754>.Acessoem: 02 jan. 2013.doi: 10.1016/j. vetpar.2006.08.011.

LAFLAMME, D.P. Development and validation of a body condition score system for dogs: a clinical tool. Canine Practice, v.22, n.3, p.10-15, 1997.

LOBATO, J.et al. Detection of immunoglobulin G antibodies to Neosporacaninum in humans: high Seropositivity rates in patients who are infected by human immunodeficiency virus or have neurological disorders. Clinical and Vaccine Immunology, v.13, n.1, p.84-89, 2006. Disponível em: <http://cvi.asm.org/ content/13/1/84.full>.Acesso em: 23 nov. 2012.doi:10.1128/ CVI.13.1.84-89.2006.

LUFT, B.J.; REMINGTON, J.S. Toxoplasmic encephalitis in AIDS. Clinical Infectious Diseases, v.15, p.211-222, 1992. Disponível em: <http://cid.oxfordjournals.org/content/15/2/211>. Acesso em: 23 jan. 2013.doi: 10.1093/clinids/15.2.211.
MEERBURG, B.G. et al. Neospora caninum and Toxoplasma gondii in brain tissue of feral rodents and insectivores caught on farms in the Netherlands. Veterinary Parasitology, v.184, n.24, p.317-320, 2012. Disponível em: <http://www.sciencedirect. com/science/article/pii/S0304401711006030>. Acesso em: 02 jan. 2013. doi: 10.1016/j.vetpar.2011.09.001.

MOURA, A.B. et al. Ocorrência de anticorpos e fatores de risco para infecção por Toxoplasma gondii em cães, nas cidades de Lages e Balneário Camboriú, Santa Catarina, Brasil. Revista Brasileira Parasitologia Veterinária, v.18, n.3, p.52-56, 2009. Disponível em: <http://www.cbpv.com.br/rbpv/ documentos/1832009/rbpv.01803009.pdf $>$. Acesso em: $10 \mathrm{dez}$. 2012.doi:10.4322/rbpv.01803009.

SPEER, C.A. et al. Comparative ultrastructure of tachyzoites, bradyzoites, and tissue cysts of Neosporacaninum and Toxoplasma gondii. International Journal for Parasitology, v.29, p.15091519, 1999. Disponível em: <http://www.sciencedirect.com/ science/article/pii/S0020751999001320>. Acesso em: 05 set. 2012. doi: 10.1016/S0020-7519(99)00132-0

TEIXEIRA, W.C. et al. Freqüência de cães reagentes para Neosporacaninumem São Luís, Maranhão. Arquivo Brasileiro Medicina Veterinária e Zootecnia, v.58, n.4, p.685-687, 2006.Disponível em: <http://www.scielo.br/pdf/abmvz/v58n4/ a38v58n4.pdf>. Acesso em: 10 dez. 2012. doi: 10.1590/S010209352006000400038 .

TRANAS, J. et al. Serological evidence of human infection with the protozoan Neosporacaninum. Clinical and Diagnostic Laboratory Immunology, v.6, n.5, p.765-767, 1999. Disponível em:<http://www.ncbi.nlm.nih.gov/pmc/articles/PMC95770/>. Acesso em: 23 nov. 2012.

ULLMANN, L.S. et al.Ações de vigilância continuada, papel do cão como sentinela para toxoplasmose. Revista Brasileira de Parasitologia Veterinária, v.17, n.1, p.345-347, 2008. Disponível em: <http://cbpv.com.br/rbpv/documentos/17sul.12008/ ProtozoolNota_008.pdf>. Aceeso em: 10 out. 2012. 